\title{
Neurosurgeons' responses to changing Medicare reimbursement
}

\author{
Joshua M. Rosenow, M.D., ${ }^{1}$ and Katie O. OrRico, J.D. ${ }^{2}$ \\ ${ }^{1}$ Department of Neurological Surgery, Northwestern University Feinberg School of Medicine, Chicago, \\ Illinois; and ${ }^{2} A A N S / C N S$ Washington Office, Washington, DC
}

\begin{abstract}
Object. Medicare reimbursement for physician services has been declining even as the number of Medicare enrollees has been increasing. The number of Medicare participants will only continue to grow as the American population ages and the Patient Protection and Affordable Care Act goes into effect. Efforts to increase reimbursement for physician services through Medicare are often met with data showing that most neurosurgeons continue to participate in the program despite these cutbacks. To better understand this dichotomy, practicing neurosurgeons were surveyed to gauge their response to cutbacks in the Medicare program beyond just their participation status.

Methods. An Internet-based survey invitation was emailed to 3469 practicing neurosurgeons. Reminder emails were sent at intervals over several weeks to help increase the response rate.

Results. Among respondents, an overwhelming percentage (96.8\%) participated in Medicare. The neurosurgeons indicated that about one-third of their patient population was covered by Medicare. They also reported limiting the number of Medicare patients they see through a variety of mechanisms: only seeing Medicare patients with a specific diagnosis or from certain referring physicians or limiting the number of appointment slots for Medicare patients. Many respondents stated that further declines in Medicare reimbursement would lead to a reduction in their participation.

Conclusions. While most responding neurosurgeons do participate in the Medicare program, a substantial proportion modulates their participation through a variety of mechanisms. These barriers to care access for Medicare patients are only expected to become greater if further declines in reimbursement are implemented through the program. (http://thejns.org/doi/abs/10.3171/2014.8.FOCUS14427)
\end{abstract}

KEY WoRds $\quad$ Medicare $\quad$ neurosurgery $\quad$ access to care
reimbursement

$\mathrm{F}$ EDERALLY funded health insurance programs such as Medicare are increasingly at the center of the health system reform debate. With an annual budget of over $\$ 500$ billion, Medicare controls a significant amount of the more than $\$ 2.5$ trillion spent annually on health care in the United States. ${ }^{3}$ Moreover, decisions made by the Centers for Medicare and Medicaid Services (CMS) regarding what services to cover and how much to reimburse for these services set the tone for many private insurers as well. The amount budgeted for Medicare reimbursement for physician services is nominally determined in part by the sustainable growth rate (SGR) formula. ${ }^{4}$ Ostensibly, this is a zero-sum total that mandates that overages in 1 year be repaid in downstream years by reductions in spending. However, for several years these reductions have been negated by last minute congressio-

\footnotetext{
Abbreviations used in this paper: ACO = accountable care organization; CMS = Centers for Medicare and Medicaid Services; RBRVS = resource-based relative value scale; RVU = relative value unit; SGR = sustainable growth rate.
}

nal action, leading to an ever-growing SGR "deficit" that hangs over the program.

As of 2010, 46 million Americans were enrolled in the Medicare program. ${ }^{3}$ As the median age of the American population increases in the coming years, this number is expected to grow substantially, along with the total costs of enrollees' health care. Recent efforts to reform the health care system have focused on containing costs. Physicians, in turn, have argued that Medicare reimbursement levels have already been reduced to the point that they do not cover the costs of providing care. Given this unfavorable economic equation, many physicians have threatened to cease participation in the Medicare program, leaving enrollees with an increasingly difficult hunt for physicians to care for them. In response to this threat, CMS often counters by demonstrating that, over time, an increasing percentage of neurosurgeons have been participating in the program. ${ }^{5}$ The percentage of neurosurgeons who are Medicare-participating physicians has increased from $76.9 \%$ in 1994 to $96.8 \%$ in 2009 . The more current rate even exceeds the proportion of all physicians 


\section{J. M. Rosenow and K. O. Orrico}

(96.3\%), neurologists $(96.1 \%)$, otolaryngologists $(96.2 \%)$, plastic surgeons $(91.1 \%)$, and internal medicine physicians $(96.2 \%)$ and is just below that of general surgeons (97.3\%), orthopedic surgeons (97.6\%), and cardiac surgeons $(98.1 \%) .^{5}$

Despite these data, conversations with practicing neurosurgeons led us to believe that many physicians were modifying their participation in the Medicare program in ways more subtle than simply changing their overall participation status. To better understand the current situation and the possible effects of recently implemented health care reform legislation, we conducted a survey of practicing neurosurgeons.

\section{Methods}

An Internet-based survey was created and an email request was sent to 3469 practicing neurosurgeons ( $A p$ pendix). Ninety-two emails were undeliverable. Reminder emails were sent out at intervals over several weeks to encourage participation. Reponses were collated and tabulated by Perception Solutions (Aurora, IL). This was intended as a simply survey, and no formal validation process was undertaken because we believed that the questions were not amenable to the reformatting involved in this process. Moreover, we believed that the solicited sample size (> 3000 surgeons) and the wide variation in geography, practice type, and surgeon demographics would help to ameliorate any issues in not undertaking a formal validation process.

Statistics were performed with SigmaStat 2.0 (SPSS). Trends were analyzed using a linear regression model. A $\mathrm{p}<0.05$ was prospectively determined to be significant.

\section{Results}

A total of 678 responses were received, making for an overall response rate of $19.5 \%$. This gives the survey a 95\% confidence level that the responses are accurate to within $\pm 5 \%$.

\section{Participating Status}

Of the respondents, $656(96.8 \%)$ reported themselves as participating Medicare physicians. Fifteen (2.2\%) were nonparticipating physicians, and 7 (1.0\%) had opted out of the program and privately contract with Medicare patients.

\section{Practice Demographics}

California (64 respondents), Florida (40), Georgia (22), Illinois (25), North Carolina (24), New York (37), Ohio (21), Pennsylvania (26), Tennessee (22), and Texas (43) were the top 10 states in which survey respondents were located. Chicago (12), New York (11), Atlanta (9), Houston (9), and Los Angeles (9) were the top 5 cities in which survey respondents were located.

Physicians in urban practices made up $35.7 \%$ of the sample (242 respondents), whereas urban/suburban practitioners represented $29.4 \%$ (199 respondents; Table 1). Suburban $(20.6 \%)$ and rural $(7.2 \%)$ practices were also represented. The survey question was unanswered by 48 respondents. One hundred percent of rural practitioners and 95\% of suburban practitioners were participating physicians, and rates of Medicare participation by urban/suburban and suburban practitioners fell between these values.

One hundred six respondents $(15.6 \%)$ listed themselves as being in solo practice, versus 235 (34.7\%) in a single specialty group, $143(21.1 \%)$ in a multispecialty group, and $122(18.0 \%)$ in a faculty practice plan. Twentyfour listed their type of practice as "other." The survey question was unanswered by the other 48 respondents.

The greatest number of physicians, 182, described their group size as 5 or fewer physicians, as opposed to 125 in groups of 5-10 physicians, 93 in groups of 11-25 physicians, 9 in groups of $26-50$ physicians, and 90 in groups with more than 50 physicians, and 179 respondents did not answer the survey question. (Original phrasing on the survey included the overlap in the number of physicians at the number 5 and is therefore reported as such.) Participation status did not vary significantly across group size, ranging from $96.7 \%$ in the smallest groups to $98.9 \%$ in the largest $\left(p=0.067, r^{2}=0.725\right)$.

\section{Medicare Patient Population}

The approximate percentage of patients cared for by neurosurgeons under the Medicare program was $32.8 \%$ overall. The rate ranged from $31 \%-40 \%$ across practices stratified by location and $28.8 \%-43.9 \%$ across practices stratified by type. The highest proportions were noted in the "other" category of practice type and in rural practices, whereas the lowest proportions were in faculty practice plans and urban practices.

Most responding neurosurgeons (489 [77.0\%] of the 635 respondents on this survey question) treated all new Medicare patients. However, $47.2 \%$ of these physicians were contractually obligated to do so by a hospital, group practice, or other entity. This percentage of obligated physicians increased significantly with increasing practice complexity $(19.4 \%$ for solo practitioners to $84.2 \%$ for practitioners in faculty practice plans; $\mathrm{p}=0.02, \mathrm{r}^{2}=$ 0.960 ) but did not significantly increase across practice locations or sizes.

A small percentage of neurosurgeons (2.7\%) reported that they had not provided services to Medicare patients in the previous year. This was mostly attributable to low reimbursements (27.8\%) and burdensome administrative requirements $(33.3 \%)$.

The majority of neurosurgeons (348 [54.6\%] of 637 respondents) responded that the percentage of their patients covered by Medicare was roughly stable as compared with 3 years ago. More than one-third of respondents $(37.7 \%)$ stated that this proportion had increased over the same time period. This observation was most common among physicians in single specialty groups (40.3\%), in practices with 5-10 neurosurgeons (44.7\%), and in urban/suburban practices with rural outreach (43.0\%). Most of those (46.7\%) who thought that the proportion had increased believed that the increase was attributable to patients seeking more care than they had previously, but this belief was less frequently held as the respondent's practice complexity increased $\left(\mathrm{p}=0.033, \mathrm{r}^{2}\right.$ $=0.936$ ). Solo practitioners most frequently $(52.6 \%)$ listed this response, as opposed to respondents in single spe- 


\section{Neurosurgeons and Medicare}

TABLE 1: Medicare participation status of survey respondents*

\begin{tabular}{|c|c|c|c|c|}
\hline Category & Total No. & $\begin{array}{c}\text { Participating Medicare } \\
\text { Physician }\end{array}$ & $\begin{array}{l}\text { Nonparticipating } \\
\text { Physician }\end{array}$ & $\begin{array}{l}\text { Physician Opted Out } \\
\text { Privately Contracting }\end{array}$ \\
\hline no. of respondents & 678 & 656 & 15 & 7 \\
\hline \multicolumn{5}{|l|}{ practice location } \\
\hline urban & 242 & 232 & 9 & 1 \\
\hline suburban & 140 & 133 & 3 & 4 \\
\hline rural & 49 & 49 & 0 & 0 \\
\hline urban/suburban w/ rural outreach & 199 & 195 & 2 & 2 \\
\hline NR & 48 & 47 & 1 & 0 \\
\hline \multicolumn{5}{|l|}{ type of practice } \\
\hline solo practitioner & 106 & 99 & 5 & 2 \\
\hline single specialty & 235 & 228 & 4 & 3 \\
\hline multispecialty & 143 & 139 & 3 & 1 \\
\hline faculty practice plan & 122 & 120 & 1 & 1 \\
\hline other & 24 & 23 & 1 & 0 \\
\hline NR & 48 & 47 & 1 & 0 \\
\hline \multicolumn{5}{|l|}{ no. of physicians in practice } \\
\hline 5 or fewer & 182 & 176 & 4 & 2 \\
\hline $5-10$ & 125 & 121 & 2 & 2 \\
\hline $11-25$ & 93 & 91 & 2 & 0 \\
\hline $26-50$ & 9 & 9 & 0 & 0 \\
\hline$>50$ & 90 & 89 & 0 & 1 \\
\hline NR & 179 & 170 & 7 & 2 \\
\hline
\end{tabular}

* NR = no response.

cialty groups $(51.6 \%)$, multispecialty groups $(44.4 \%)$, and faculty practice plans $(39.5 \%)$.

Of the 49 neurosurgeons $(7.7 \%)$ who had cared for a reduced number of Medicare patients, more than half (29 neurosurgeons [59.2\%]) stated they deliberately worked to reduce the number of Medicare patients they see because of poor reimbursements. This was especially true among solo practitioners; that is, $72.7 \%$ of neurosurgeons in solo practice took these steps because of insufficient reimbursements. Moreover, 33 physicians whose Medicare population had remained roughly steady revealed that they had taken steps to prevent increases. Only a very small number of neurosurgeons $(1.3 \%)$ had deliberately worked to increase the number of Medicare patients in their practice.

\section{Methods of Limiting Medicare Patients}

While 231 neurosurgeons $(47.2 \%)$ were contractually obligated to treat all new Medicare patients, a substantial proportion of the respondents (138 [21.7\%] of 635) only treat certain new Medicare patients. (Note that 258 respondents see all Medicare patients but are not contractually obligated to do so.) Methods of limiting new Medicare patients involve seeing direct referrals only (57.2\%), accepting only those with "special circumstances" (for example, a relative of another patient), or seeing only those with a diagnosis that falls within a subspecialty or academic interest. Forty percent (55 of 138) of the neurosurgeons in this group stated that they actively assigned a lower priority to Medicare patient requests for appointments than to patients with other insurances.

These limiting steps were especially frequent among the smaller practitioner groups, that is, the solo practitioners and practitioners in groups with $\leq 5$ physicians. A large proportion of the solo practitioners (73.5\%) and small groups (63.6\%) who limited Medicare patients only saw direct referrals, as they attempted to keep referral bases intact by accepting poorly reimbursing patients in the hopes of continuing to receive other patients from these referring physicians.

Appointment slots for new Medicare patients were limited by $114(18.3 \%)$ of the 622 neurosurgeons who responded (Table 2). The percentage of neurosurgeons who took this step decreased as the practice type became more complex: $26 \%$ of solo practitioners versus $19.5 \%$ of those in a single specialty group, $15.0 \%$ of those in a multispecialty group, and $14.4 \%$ of those in a faculty practice plan. This trend approached significance $\left(\mathrm{p}=0.053, \mathrm{r}^{2}=0.897\right)$. When we stratified limiting new Medicare patients by practice location, we found that rural practices limited slots the least often (14.3\%), whereas suburban practices $(23.5 \%)$ limited them the most often. Fifty-two respondents $(8.4 \%)$ limited both new and established Medicare appointment slots.

Among the entire group of respondents, the average wait time for an appointment for a Medicare patient was 24.1 days. Even though faculty practice plans limit slots the least, they actually had the longest mean wait time 


\section{J. M. Rosenow and K. O. Orrico}

TABLE 2: Percentage of respondents indicating that they limit the number of available appointment slots for Medicare patients*

\begin{tabular}{lcc}
\hline \multicolumn{1}{c}{ Category } & $\begin{array}{c}\text { For New \& } \\
\text { Established } \\
\text { Medicare Patients }\end{array}$ & $\begin{array}{c}\text { For New } \\
\text { Medicare Patients }\end{array}$ \\
\hline no. of respondents & 52 & 114 \\
practice location (\%) & & \\
$\quad$ urban & 7.6 & 18.6 \\
suburban & 8.8 & 23.5 \\
rural & 8.2 & 14.3 \\
urban/suburban w/ rural & 8.8 & 14.5 \\
$\quad$ outreach & & \\
type of practice (\%) & 11.5 & 26.0 \\
solo practitioner & 8.2 & 19.5 \\
single specialty & 8.6 & 15.0 \\
multispecialty & 5.1 & 14.4 \\
faculty practice plan & & \\
no. of physicians in practice (\%) & 8.4 & 19.0 \\
5 or fewer & 9.8 & 18.7 \\
$5-10$ & 6.8 & 17.0 \\
$11-25$ & 11.1 & 0.0 \\
$26-50$ & 3.4 & 11.2 \\
$>50$ & & \\
\hline
\end{tabular}

* Values indicate percentage of respondents, except for the number of respondents.

for an appointment (28.8 days), while the single specialty practices had the shortest wait time (22.3 days).

\section{Collateral Effects}

When asked about the environment for medical care for Medicare patients, the neurosurgeons noted several important trends. A substantial proportion (64.8\%) of the 622 respondents stated that physicians in their community were increasingly referring complex Medicare patients out to other physicians rather than caring for them themselves. Over half $(52.4 \%)$ noted that this was occurring for even fairly routine cases, and many $(60.5 \%)$ noted that these patients were specifically being referred to tertiary care centers, thus indicating physicians' growing unwillingness to treat Medicare patients.

Importantly, more than two-thirds of respondents (67.2\%) asserted that it is more difficult for them to refer Medicare patients to other medical and surgical specialists, indicating that this is not simply a phenomenon among neurosurgeons. In fact, $62.6 \%$ of the respondents specifically noted that it was more difficult to find a primary care physician who would accept Medicare patients.

\section{Future Plans}

Asked about their future plans as Medicare reimbursements decline, $27 \%$ of 633 neurosurgeons said that they plan to decrease the number of established Medicare patients they see, and $39.5 \%$ will decrease the number of new Medicare patients (Table 3). Interestingly, 18.3\% stated that they will completely stop taking new Medicare patients. Once again, the percentage of respondents who will stop seeing new Medicare patients declined significantly across practice types: $30.8 \%$ of solo practitioners, $19.9 \%$ of those in a single specialty group, $16.4 \%$ of those in a multispecialty group, and $8.5 \%$ of those in a faculty practice plan $\left(\mathrm{p}=0.018, \mathrm{r}^{2}=0.964\right)$. Decreasing practice complexity made it more likely that a neurosurgeon would reduce the number of established or new Medicare patients or cease taking them altogether, but only the latter reached significance $\left(\mathrm{p}=0.019, \mathrm{r}^{2}=0.963\right)$.

According to the respondents, short of these measures, multiple other measures would be taken if Medicare payments continued to decline as dictated by the SGR formula. More than half $(54.0 \%)$ stated that they would cease providing certain services to Medicare patients, and almost half (46.6\%) would begin referring complex patients to other physicians. Other key changes planned included reducing the length of the appointment slot for Medicare patients (52.9\%), reducing office staff $(50.8 \%)$, deferring the purchase of new equipment (53.8\%), and deferring information technology purchases (40.9\%). Not unexpectedly, these changes were most frequently reported by neurosurgeons in solo practice.

Overall, $14.4 \%$ of responding neurosurgeons stated that declining Medicare reimbursements would cause them to leave the practice of medicine altogether. Moreover, $27.5 \%$ stated that they would close some of their offices, and $27.2 \%$ would discontinue rural outreach services. One-quarter $(25.0 \%)$ of solo practitioners and $18.4 \%$ of rural physicians stated that they would cease practicing medicine. In fact, rural practitioners more frequently answered that they were likely to retire $(12.2 \%)$ or close and/ or sell their practice $(16.3 \%)$ than the neurosurgeons in urban (5.1\% and 5.9\%, respectively) or suburban practices (7.4\% and $8.8 \%$, respectively).

These plans also varied by geographic region of the country. We divided physicians along the geographic lines of the quadrants used by the American Association of Neurological Surgeons and the Council of State Neurosurgical Societies. ${ }^{2}$ In the Northeast, $66.7 \%$ of responding neurosurgeons deliberately reduced Medicare patients because of poor reimbursements, and $14.3 \%$ plan to stop taking Medicare patients if the poor reimbursement trend continues. In the Southwest, these respective figures were $50 \%$ and $26 \%$; in the Northwest, $50 \%$ and $13 \%$; and in the Southeast, $73.3 \%$ and $21 \%$.

\section{Discussion}

Neurosurgeons are deeply concerned about trends in physician reimbursement under the Medicare program. Yearly uncertainty regarding the payment updates dictated by the SGR formula is compounded by newly passed fundamental health system reform.

\section{Brief History of the Medicare Physician Fee Schedule}

Until 1975, physicians were paid based on the usual and customary charges prevalent in their geographic regions. Beginning in 1975, increases in fees were limited by the growth of the Medicare Economic Index (MEI). 
Neurosurgeons and Medicare

TABLE 3: Probable effect of further reimbursement cuts on Medicare participation status*

\begin{tabular}{lccc}
\hline \multicolumn{1}{c}{ Category } & $\begin{array}{c}\text { Reduce Established } \\
\text { Medicare Patients }\end{array}$ & $\begin{array}{c}\text { Reduce New Medicare } \\
\text { Patients }\end{array}$ & $\begin{array}{c}\text { Cease Taking New } \\
\text { Medicare Patients }\end{array}$ \\
\hline $\begin{array}{l}\text { no. of respondents } \\
\text { practice location (\%) }\end{array}$ & 171 & 250 & 116 \\
$\quad$ urban & 23.3 & 37.3 & 19.9 \\
$\quad$ suburban & 35.3 & 47.8 & 19.9 \\
rural & 24.5 & 34.7 & 14.3 \\
urban/suburban w/ rural outreach & 26.9 & 37.3 & 17.6 \\
type of practice (\%) & & & 30.8 \\
solo practitioner & 36.5 & 41.3 & 19.9 \\
single specialty & 31.2 & 46.3 & 16.4 \\
multispecialty & 28.6 & 40.7 & 8.5 \\
faculty practice plan & 11.0 & 26.3 & 19.6 \\
no. of physicians in practice (\%) & & & 21.1 \\
5 or fewer & 33.0 & 44.1 & 13.6 \\
$5-10$ & 22.0 & 39.8 & 22.2 \\
11-25 & 28.4 & 54.5 & 4.5 \\
$26-50$ & 22.2 & 22.2 & 18.0 \\
$>50$ & 12.4 & &
\end{tabular}

* Values indicate percentage of respondents, except for the number of respondents.

The current model of the Medicare Physician Fee Schedule was implemented in 1992, along with the concept of the resource-based relative value scale (RBRVS), which grew out of a study by William C. Hsiao of the Harvard School of Public Health. The RBRVS attempts to assign relative values to disparate types of physician services, for example, an office consultation and a craniotomy for brain tumor resection. ${ }^{1}$

The fundamental unit of the RBRVS is the relative value unit (RVU). Each type of physician service has a designated cost in RVUs attributed to three components-physician work, practice expense, and professional liability. The overall physician reimbursement is determined by taking the sum of the three RVU components and multiplying them by the Medicare conversion factor (expressed in dollars per RVU) set annually by the CMS. There is also an adjustment factor to account for geographic differences in the cost of providing care. The initial published conversion factor is frequently altered near the end of the calendar year as physician groups and Congress negotiate the overall CMS budget for the coming year (www.csnsonline.org). ${ }^{8}$

Over all of this is the SGR, the legislated growth in the overall CMS physician services budget. Theoretically, this is a zero-sum formula in which any overage from 1 year must be repaid in subsequent years. Consequently, physicians are constantly arguing for positive updates in the conversion factor that inevitably result in the actual CMS spending exceeding the budgeted amount. This leads the CMS to schedule a negative update the next year, only to have it overturned by more concerted physician lobbying. The cumulative effect is an annual threat of an ever-increasing cut in the conversion factor that is halted at the last minute in what has become known in the press as the "doc fix." The last year of a negative update to the conversion factor was 2004 .

The 2 decades since the introduction of this system have seen many battles over these values. There is a constant tug of war between subspecialists and primary care providers over the relative valuation of procedure versus "cognitive" work. Moreover, each new procedure requires a new code. Not only are there battles over whether an additional code should even exist, but each code requires a new RVU valuation, which in turn means that other similar codes must be decreased to compensate. Moreover, all codes are periodically reviewed, setting off battles as physician specialties diligently try to protect the current RVU values from cuts. Lastly, all physicians argue together for improvements in the conversion factor.

\section{Implications of the Survey Results}

These survey data demonstrate that neurosurgeons have already begun to make significant changes in their practice patterns as regards Medicare patients. Importantly, these changes are not reflected in the statistics of the number of participating neurosurgeons and thus cannot be easily tracked by the CMS. Therefore, reliance on gross measures of physician participation status may significantly underestimate the impact of reimbursement trends on Medicare patient access to neurosurgical care.

The survey results are somewhat limited by the low response rate (approximately 20\%) despite our efforts to boost response by sending out multiple email reminders. Physicians may have been disinclined to complete the survey given its length, although we did try to minimize the completion burden while still endeavoring to obtain the information we desired. Moreover, the survey was only distributed via email, so any physician who did not check 


\section{J. M. Rosenow and K. O. Orrico}

email for the address used would have missed the link, as would any physician whose spam filters aggressively removed the email before it could be seen. In addition, the survey email may simply have been treated as part of the tide of email that neurosurgeons receive from our national organizations and deleted without being read. Lastly, we did not put this survey through a formal validation process, leaving true validation somewhat open to interpretation.

\section{Possible Implications of Health Care Reform}

The Patient Protection and Affordable Care Act of 2010 is intended to enable millions more Americans to have health insurance. However, the possession of individual health insurance does not necessarily guarantee access to health care. The results of this survey indicate that while it may be possible to find a neurosurgeon who accepts Medicare, it may be very difficult to actually obtain care, at least in part because of the poor reimbursement rates under the program. The problem highlighted here is one that concerns the federal government as well, as indicated by the announced plan (later dropped) for a government "secret shopper" survey of access to primary care physicians by Medicare patients.

There has been debate about the presence and possible significance of geographic variations in spending, outcomes, and quality in the Medicare program. Our survey data imply that geography may play a significant role going forward. Specifically, a smaller percentage of responding neurosurgeons in the southeastern and southwestern quadrants of the country currently accept all Medicare patients, and neurosurgeons in these regions more frequently responded that they would cease caring for both new and established Medicare patients should reimbursements decline further. Given that recent population trends have favored growth in these regions,${ }^{6}$ these attitudes may have a great impact on access to care as the population in these regions ages.

Stratifying results by practice complexity revealed that solo neurosurgeons appear to be an endangered species. These physicians were less likely to see all new Medicare patients and more likely to reduce the number of Medicare patients they see because of reimbursement issues. Solo practitioners were also more likely to stop caring for Medicare patients, sell their practice, retire, or refer complex cases. However, they were less likely to rely on physician extenders, such as nurse practitioners and physician assistants. This may be attributable to their inability to afford the additional expense.

\section{Alternative Physician Payment Models}

Currently, multiple alternative models of physician reimbursement are in operation, testing, or discussion.? In general, these methods tend to tie physician payment to patient outcomes and overall cost of patient care, as opposed to the traditional fee for service reimbursement. Most methods also involve partnerships between physicians and hospitals, and some may include third party payers as well. Accountable care organizations (ACOs) are one of the most popular versions being explored at this time, because of their promulgation by the Affordable Care Act. An ACO brings together hospitals, physi- cians, and other caregivers in an effort to improve patient outcomes. While physicians are often still reimbursed in a similar way for the work performed, there are financial incentives tied to specific patient outcomes. Moreover, gainsharing may be enabled for any savings accrued as a result of ACO initiatives.

Bundled payments are being used more often for certain episodes of care that lend themselves to more formulaic care pathways, such as total joint replacement and certain aspects of surgical spine care. This model forces the physicians and hospitals to split a single payment for an entire episode of care. These arrangements provide a significant incentive for physicians and hospitals to collaborate, as both physician and hospital reimbursements are dependent on efforts from both parties to improve quality, reduce costs, and reduce adverse events. Most of these bundled payment schemes continue to suffer from criticisms such as the need to risk adjust any payments for the specific comorbidities of individual patients, lest the programs serve to encourage treatment of only the simplest cases and healthiest patients.

\section{Conclusions}

The majority of neurosurgeons continue to participate in the Medicare program. However, their participation is not absolute and appears to be far from guaranteed. The coming implementation of health system reform and a possible long-term fix to the SGR formula will have significant implications for ongoing access to neurosurgical care for the Medicare population.

\section{Disclosure}

The authors report no conflict of interest concerning the materials or methods used in this study or the findings specified in this paper.

Author contributions to the study and manuscript preparation include the following. Conception and design: both authors. Acquisition of data: Rosenow. Analysis and interpretation of data: Rosenow. Drafting the article: both authors. Critically revising the article: both authors. Reviewed submitted version of manuscript: both authors. Approved the final version of the manuscript on behalf of both authors: Rosenow. Statistical analysis: Rosenow.

\section{Appendix}

\section{Medicare Physician Payment Survey}

1. What is your Medicare participation status?

$\square$ Participating Physician

$\square$ Nonparticipating Physician

$\square$ Opted out for 2 years and privately contract with Medicare patients

2. During the last 12 months, did you provide any services to patients whose principal source of payment was Medicare?

$\square$ Yes (SKIP TO QUESTION 3) $\square$ No

2a. Why haven't you provided services to patients whose principal source of payment was Medicare? (CHECK ALL THAT APPLY)

$\square$ Payment rates are too low

$\square$ Administrative requirements are too much of a burden

$\square$ Not many Medicare patients in the community where I practice

$\square$ My specialty does not see many Medicare patients

$\square$ Other (PLEASE SPECIFY)

(SKIP TO QUESTION 12) 


\section{Neurosurgeons and Medicare}

3. Approximately what percentage of your current patients is covered by Medicare? $\%$

4. Is this percentage higher, lower or about the same as it was 3 years ago?

$\square$ Higher

$\square$ Lower

$\square$ About the Same

4a. If higher, why do you believe that is so? (CHECK ALL THAT APPLY)

$\square$ My Medicare patients seek more care than they used to

$\square$ I need to see patients more often to regulate drugs and/or chronic conditions

$\square$ I have deliberately tried to attract Medicare patients to my practice because Medicare pays better than private plans

$\square$ A lot of care that used to be provided by hospitals can now be provided in my office

$\square$ As I have gotten older, so have my patients

$\square$ Other (PLEASE SPECIFY)

4b. If lower, why do you believe that is so? (CHECK ALL THAT APPLY)

$\square$ I have deliberately reduced the number of Medicare patients in my practice due to low pay

$\square$ My patient mix has changed due to demographic changes in my community

$\square$ My patient mix has changed due to changes in technology, practice location, or development of specialized clinical expertise

$\square$ Other (PLEASE SPECIFY)

4c. If about the same, why do you believe that is so? (CHECK ALL THAT APPLY)

$\square$ The number of Medicare patients seeking my services has remained pretty steady

$\square$ I have taken steps to prevent increases in the number of Medicare patients I see

$\square$ Other (PLEASE SPECIFY)

5. Do you currently agree to treat all new Medicare patients, some new Medicare patients, or no new Medicare patients who contact you?

$\square$ All new Medicare patients

Are you contractually obligated by a hospital, group practice, or other entity to do this?

$$
\square \text { Yes } \square \text { No }
$$

$\square$ Some new Medicare patients (CHECK ALL THAT APPLY) $\square$ Treat referrals only

$\square$ Give lower priority to Medicare patients than private pay

$\square$ Accept only patients with "special circumstances" such as having been a previous patient or the parent of a current patient

$\square$ Only those Medicare patients who require care for a certain subspecialty/academic interest

$\square$ Other (PLEASE SPECIFY)

$\square$ No new Medicare patients (CHECK ALL THAT APPLY)

$\square$ Practice is full; not taking new patients from any payer

$\square$ Payment rates are too low

$\square$ Administrative requirements are too much of a burden

$\square$ Need to see more patients to cover overhead and Medicare patients require more time

$\square$ Other (PLEASE SPECIFY)

6. If Medicare payments continue to decline, how will this affect the number of Medicare patients you treat?

$\square$ I will increase the number of NEW Medicare patients

$\square$ I will decrease the number of NEW Medicare patients

$\square$ I will stop taking any NEW Medicare patients

$\square$ I will keep the same number of NEW Medicare patients

$\square$ I will increase the number of ESTABLISHED Medicare patients

$\square$ I will decrease the number of ESTABLISHED Medicare patients $\square$ I will stop taking any ESTABLISHED Medicare Patients

$\square$ I will keep the same number of ESTABLISHED Medicare patients

$\square$ I don't know

7. If Medicare payments are cut, do you plan to make any of the following changes to your practice? (CHECK ALL THAT APPLY)

a. Stop providing any patient care

b. Retire

c. Close/sell practice

d. Significantly reduce workload/hours

e. Begin working locum tenens

f. Relocate

g. Stop providing certain services

h. Shift services from office to hospital

i. Begin referring complex cases

j. Defer purchase of information technology

k. Reduce staff

1. Defer purchase of new medical equipment

$\mathrm{m}$. Close satellite offices

n. Discontinue rural outreach services

o. Discontinue nursing home visits

p. Reduce time spent with Medicare patients

q. Increase use of nurse practitioners/physician assistants

8. In the last 3 to 5 years, which, if any, of the following changes have you observed in the environment for Medicare patients in the community where you practice?

Medicare patients with complex

problems to other doctors

b. More physicians are sending even fairly routine cases to other doctors

c. More physicians are sending Medicare patients to tertiary medical centers

d. More Medicare patients are being treated in hospital outpatient departments for conditions that could have been treated in a physician's office

e. More Medicare patients are being treated in the emergency room for conditions that could have been treated in a physician's office

f. More Medicare patients have put off needed care because they couldn't find a doctor

g. It is harder to find a primary care physician to take over my patients' care following surgery or an emergency room visit

h. It has gotten harder to refer patients to certain medical and surgical specialists

i. Many Medicare patients now have to travel further to get needed care

9. Do you limit the number of Medicare patient appointment slots in your practice?

$\square$ Yes, only for new Medicare patients

$\square$ Yes, for all Medicare patients (new and established)

$\square$ No

10. If you do limit the number of Medicare patient appointment slots in your practice, how is this done? 


\section{J. M. Rosenow and K. O. Orrico}

11. If you treat Medicare patients, what is the average waiting time for a patient appointment for:

$\square$ New Medicare patients

$\square$ Established Medicare patients

12. To enable us to identify potential trends that are specific to location and type or practice, we would like to get some specific information about you and your practice, beginning with the state and city where your main practice is located.

a. City

b. State

13. Which of these categories best describe your practice? (CHECK ALL THAT APPLY)

$\square$ Rural

$\square$ Urban

$\square$ Suburban

$\square$ Urban/Suburban with rural outreach

14. Which of these categories best describe your type of practice? (CHECK ALL THAT APPLY)
$\square$ Solo Practitioner
$\square$ Single Specialty Group
$\square$ Multispecialty Group
$\square$ Faculty Practice Plan
$\square$ Other (PLEASE SPECIFY)

15. If in a group or faculty practice plan, how many physicians are there?
$\square 5$ physicians or fewer
$\square 5$ to 10 physicians
$\square 11$ to 25 physicians
$\square 26$ to 50 physicians
$\square$ More than 50 physicians

16. What is your practice or subspecialty focus? (CHECK ALL THAT APPLY)

$\square$ General neurosurgery

$\square$ Pain

$\square$ Pediatrics

$\square$ Spine and Peripheral Nerve

$\square$ Stereotactic and Functional

$\square$ Trauma

$\square$ Tumor

$\square$ Other (PLEASE SPECIFY)

\section{References}

1. American Medical Association: History of the RBRVS. (http://www.ama-assn.org/ama/pub/physician-resources/solu tions-managing-your-practice/coding-billing-insurance/medi care/the-resource-based-relative-value-scale/history-of-rbrvs. page?) [Accessed September 18, 2014]

2. Centers for Medicare and Medicaid Services: Estimated Sustainable Growth Rate and Conversion Factor, for Medicare Payments to Physicians in 2011. (http://www.cms.gov/ Medicare/Medicare-Fee-for-Service-Payment/Sustainable GRatesConFact/Downloads/sgr2011f.pdf] [Accessed September 18, 2014]

3. Centers for Medicare and Medicaid Services: Percentage of Medicare Participating Physicians and Limited License Practitioners. Washington, DC: CMS, 2010

4. Congressional Budget Office: CBO's August 2010 Baseline: Medicare. (http://www.cbo.gov/sites/default/files/cbofiles/ attachments/MedicareAugust2010FactSheet.pdf) [Accessed September 18, 2014]

5. Evans JL: Medicare Physician Reimbursement. (http:// www.healthlawyers.org/Events/Programs/Materials/Documents/MM10/evans.pdf) [Accessed September 18, 2014]

6. Tavernise S, Zeleny J: South and west see large gains in latest census. New York Times. December 21, 2010 (http://www. nytimes.com/2010/12/22/us/22census.html?_r=0) [Accessed September 18, 2014]

7. Wilensky GR: Developing a viable alternative to Medicare's physician payment strategy. Health Aff (Millwood) 33:153160,2014

8. Wilensky GR: Medicare Physician Payments: Where We've Been; Where We Need to Go. (http://www.finance. senate.gov/imo/media/doc/Wilensky\%20Statement.pdf) [Accessed September 18, 2014]

Manuscript submitted July 11, 2014.

Accepted August 22, 2014.

Please include this information when citing this paper: DOI: 10.3171/2014.8.FOCUS14427.

Address correspondence to: Joshua M. Rosenow, M.D., Department of Neurosurgery, 676 N. St. Clair St., Ste. 2210, Chicago, IL 60611.email: jrosenow@nmff.org. 